Far Eastern Entomologist

\begin{tabular}{lll}
\hline Number 422: 24-32 & ISSN 1026-051X (print edition) & January 2021 \\
\hline
\end{tabular}

https://doi.org/10.25221/fee.422.3

http://zoobank.org/References/d648b411-a388-44a5-aca7-da437fe3f207

\title{
STICK INSECTS OF THE GENUS INTERPHASMA CHEN ET HE, 2008 (PHASMIDA: PHASMATIDAE) FROM CHINA
}

\author{
B. L. Li ${ }^{1)}$, F. M. Shi ${ }^{2, *)}$, H. J. Wang ${ }^{1, *)}$
}

1) College of Agronomy, Sichuan Agricultural University, Chengdu 611130, P. R. China.

2) College of Life Sciences, Hebei University, Baoding 071002, P. R. China.

*Corresponding authors, E-mail: shif_m@126.com,wanghaijian2005@sina.com

Summary. An annotated list of the species of the genus Interphasma Chen et He, 2008 from China is given. Interphasma huayingshanense Li, Shi et Wang, sp. $\mathbf{n}$. is described from the Chinese province Sichuan. The type specimens of a new species are deposited in the collection of the Department of Plant Protection, College of Agronomy, Sichuan Agricultural University.

Key words: stick insects, Phasmida, Clitumninae, Medaurini, taxonomy, new species, fauna, Sichuan.

Б. Л. Ли, Ф. М. Ши, Х. Я. Ванг. Палочники рода Interphasma Chen et Hе, 2008 (Phasmida: Phasmatidae) Китая. // Дальневосточный энтомолог. 2021. N 422. C. 24-32.

Резюме. Приведен аннотированный список видов рода Interphasma Chen et He, 2008 из Китая. Из китайской провинции Сычуань описан Interphasma huayingshanense $\mathrm{Li}$, Shi et Wang sp. n. Типы нового вида хранятся в коллекции Департамента защиты растений (Агрономический колледж Сычуаньского сельскохозяйственного университета).

\section{INTRODUCTION}

The genus Interphasma Chen et He, 2008 was established for 11 Chinese species with $I$. lushanense Chen et He, 2008 as type species (Chen et He, 2008). So far, the genus consists of 17 species, one of which is further differentiated in two subspecies. They are all known from China with exception of I. lineatum Ho, 2020 from Vietnam (Chen et He, 2008; Chen et Zhang, 2008; Xu et al., 2010; Ho et Shi, 2013; Ho, 2017, 2020). Hennemann et Conle (2008) revised the family Phasmatidae and established the tribe Medaurini, transferring the genus Interphasma to this tribe. Here an annotated list of Chinese species of this genus is given and one new species from Sichuan province is described and illustrated.

\section{MATERIAL AND METHODS}

Due to their nocturnal behaviour, most species of Phasmida including new one were collected at night. A light-weight and water-proof head torch SupFire HL08 was used during collecting. Both sexes of new species were kept alive in a porous plastic box for mating and spawning. 
The whole body picture of specimens were photographed with a Canon EOS 550D camera equipped with a Canon EF 100mm f/2.8L IS USM and a Canon SPEEDLITE 470EX-AI flash. The other images were acquired using Leica M205A digital imaging system in College of Life Sciences, Hebei University. Measurements were taken under stereomicroscope with vernier caliper or eyepiece micrometer.

The terminology follows Clark-Sellick (1997) for the egg and Bragg (1997) for other structures.

The following abbreviations are used for the deposition of material discussed in this study: SICAU - Sichuan Agricultural University, Chengdu, China; CAU - China Agricultural University, Beijing, China; BFU - Beijing Forestry University, Beijing, China; IZCAS Institute of zoology, Chinese Academy of Sciences, Beijing, China.

\section{TAXONOMY}

Family Phasmatidae Leach, 1815

Subfamily Clitumninae Brunner von Wattenwyl, 1893

Tribe Medaurini Hennemann et Conle, 2008

Genus Interphasma Chen et $\mathrm{He}, 2008$

Type species: Interphasma lushanense Chen et He, 2008, by original designation.

DESCRIPTION. Medium size stick insects. Apterous. Body robust in female, with wrinkles and granuloids; in male body smooth, with sparse and small granulations which may be absent in some species. Head slightly extended, oblong. One pair of granules between the eyes usually present, or absent in some species. Occiput flat, with granulation or smooth in the male of some species. Antennae distinctly segmented, shorter than fore femora and shorter than half of fore femora in female. Fore femora curved basally. Legs unarmed. Mesothorax slender. Median segment and abdominal tergite II transverse in female, but abdominal tergite II length longer than width in male. Abdomen cylindrical. Female sternite VII with distinct praeopercular organ in most species, abdominal tergite IX with a protuberance in the middle of posterior margin, anal segment tectiform with truncated posterior edge. Female supra-anal plate small or indistinct; operculum boat-shaped. Male anal segment distinctly dilated into two lobes, subgenital plate cup-shaped. Cerci short and cylindrical, curved inward in male.

COMPOSITION. So far, the genus consists of 17 species distributed in China (Gansu, Guangxi, Guizhou, Jiangxi, Shaanxi, Sichuan, Xinjiang and Yunnan) and Vietnam. One new species is described below.

List of the species and subspecies of the genus Interphasma from China with description of a new species

\section{Interphasma bifidum Chen et He, 2008}

Type locality: China (Emeishan, Sichuan).

TYPE MATERIAL EXAMINED. Holotype - $\hat{\jmath}$, China: Sichuan, Emeishan, 16.VIII 1998, coll. Ding Yang (CAU).

OTHER MATERIAL EXAMINED. China: Sichuan, Emeishan, Qingyinge, 19.VIII 2017, 1 , , coll. Xue-Yong Du (SICAU).

Interphasma conicercum Chen et $\mathrm{He}, 2008$

Type locality: China (Xixiangchi, Emeishan, Sichuan). 
MATERIAL EXAMINED. China: Sichuan, Emeishan, Leidongping, 19.VIII 2017, 4우

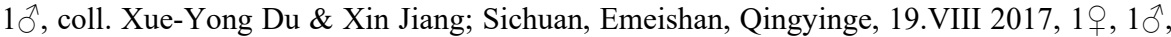
coll. Xue-Yong Du; same locality, 20.VII 2019, 2,10, coll. Hai-Jian Wang; Sichuan, Chongzhou, Anzihe, 19.IX 2016, 1ㅇ, coll. Xiao-Qiang Guo (SICAU).

\section{Interphasma elongatum elongatum Ho, 2017}

Type locality: China (Yuping, Pingbian, Yunnan).

NOTE. No material examined.

\section{Interphasma elongatum parvum Ho, 2017}

Type locality: China (Fenshuiling, Jinping, Yunnan).

MATERIAL EXAMINED. China: Yunnan, Xishuanbanna, Manxilongla Mengsong, 16.VIII 2019, 4ㅇ, 4^, coll. Sheng-Chuan Yang \& Qi-Di Zhu (SICAU).

\section{Interphasma emeiense Chen et He, 2008}

Type locality: China (Emeishan, Sichuan).

MATERIAL EXAMINED. China: Sichuan, Chongzhou, Anzihe, 17.VIII 2017, 1ㅇ, 10ิ, coll. Xiao-Qiang Guo \& Yi-Ming Deng; Sichuan, Chongzhou, Jiulonggou, 15.IV 2016, 2 , 20̂, coll. Xiao-Qiang Guo \& Yi-Ming Deng; Sichuan, Dujiangyan, Qingchengshan, 27.V 2016, 1, coll. Xiao-Qiang Guo \& Yi-Ming Deng; Sichuan, Emeishan, Qingyinge, 20.VIII 2017, 2 +, $2 \hat{\jmath}$, coll. Xue-Yong Du \& Xin Jiang (SICAU).

\section{Interphasma fanjingense Chen et He, 2008}

Type locality: China (Fanjingshan, Guizhou).

TYPE MATERIAL EXAMINED. Holotype - $\widehat{\jmath}$, China: Guizhou, Fanjingshan, 2002 (unknown the exact data), coll. Fang-Ling Xu (BFU).

\section{Interphasma guangxiense Chen et $\mathrm{He}, 2008$}

Type locality: China (Langping, Tianlin, Guangxi).

TYPE MATERIAL EXAMINED. Holotype - + , China: Guangxi, Langping, Tianlin, 28.V 1982, coll. Ji-Kun Yang (BFU).

\section{Interphasma huanglianshanense Ho, 2017}

Type locality: China (Huanglianshan, Luchun, Yunnan).

MATERIAL EXAMINED. China: Yunnan, Puer, Simao, Yixiang, 22.VIII 2019, 1q, coll. Qi-Di Zhu (SICAU).

Interphasma huayingshanense Li, Shi et Wang, sp. $n$.

http://zoobank.org/NomenclaturalActs/2be82d22-152f-431e-bc94-1e21761fe33f

Figs $1-18$

TYPE MATERIAL. Holotype - + , China: Sichuan, Huayingshan, 13.VIII 2019, coll. Bo-Liang Li (SICAU). Paratypes: $2 \hat{\jmath}, 2$, , same locality as holotype, 13.VIII 2019, coll. BoLiang Li \& Di-Cheng Fan; eight eggs naturally laid by female types (SICAU).

DESCRIPTION. FEMALE (Figs 1, 3; 10-12, 15-18). 
Head: Oval, almost the same long as pronotum, with sparse granules. Vertex with a pair of small blackish granules on transverse ridge between compound eyes, and one irregular black mark near inner margin of compounded eye. Occiput flat, occipital furrows indistinct, with irregular and sparse granules. Genae with small granules and a broad blackish postocular stripe. Compound eyes oval, prominent. Antennae 14-segmented, reaching the middle of fore femora, scapus flat and broad, about two times length of pedicel, other segments cylindrical, 3rd segment longest.

Thorax: Apterous, with irregular granules, brown or green. Pronotum trapezoidal, slightly expanded posteriorly, posterior area of pronotum with a pair of oval blackish speckles, anterior margin concave, posterior margin truncate, transverse and longitudinal sulci crossing at the
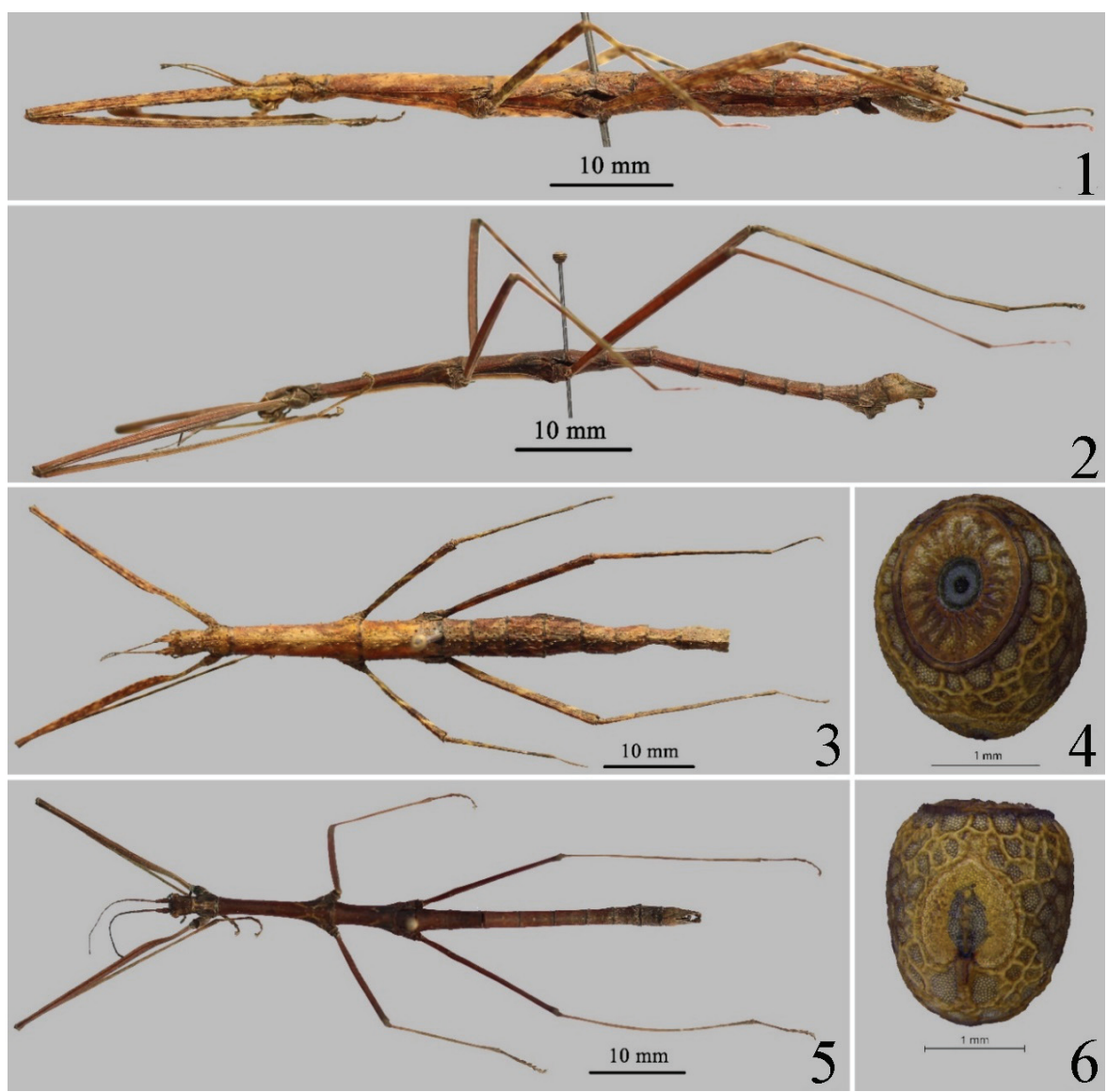

Figs 1-6. Interphasma huayingshanense sp. n.: 1, 3 - female (holotype); 2, 5 - male (paratype); 4, 6- egg; 1,2 - lateral view; 3, 5, 6- dorsal view; 4 - anterior view. 

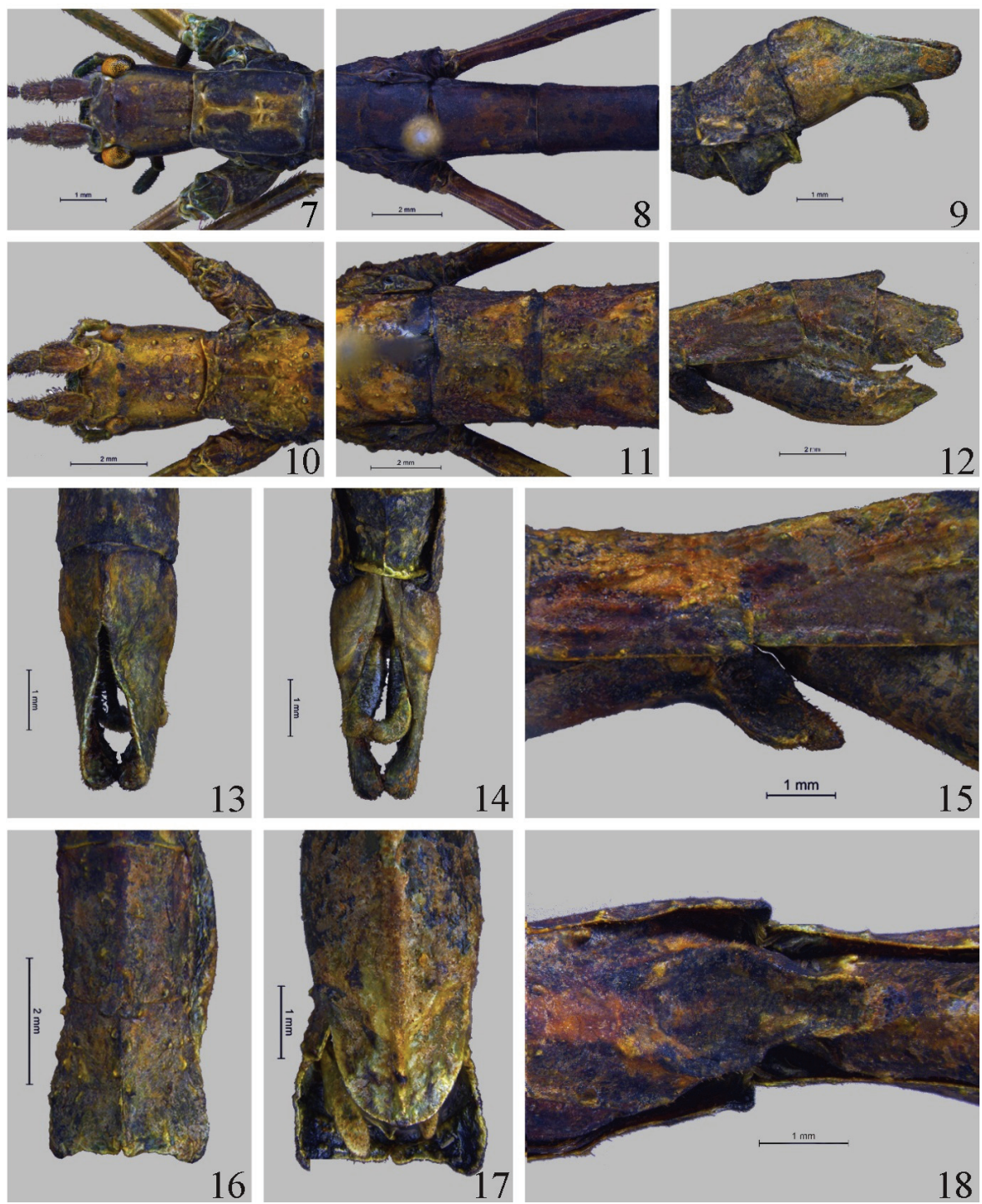

Figs 7-18. Interphasma huayingshanense sp. n.: 7-9, 13, 14 - male; 10-12, 15-18 female; 7, 10 - head and pronotum, dorsal view; 8, 11 - median segment and tergite II; 9 12-14, 16-17 - anal segment: 9, 12 - lateral view; 13, 16 - dorsal view; 14,17 - ventral view; 15,18 - sternite VII: 15 - lateral view; 18 - ventral view. 
middle, apices of transverse sulcus curved forward, not reaching lateral edges. Middle area of mesonotum and metanotum with a rhombic pale. Mesonotum and metanotum randomly covered with sparse and not uniform size granules. Mesonotum longer than metanotum and median segment combined. Metanotum about 2.5 times as long as median segment. Mesopleurae and metapleurae with sparse granules.

Abdomen: With irregular granules, brown or green. Both median segment and tergite II wider than long. Tergite III longest. Tergites II-VII with irregular longitudinal wrinkles and some irregular pale stripes. Sternite VII with distinct praeopercular organ, which broad at base and narrow at apex, surpassing base of subgenital plate. Posterior margin of tergite IX with a posteromedian hump, pointing backwards. Subgenital plate boat-shaped, apex bluntly rounded, not reaching the posterior margin of anal segment. Cerci short, gently compressed, tapering posteriorly, not reaching posterior margin of the anal segment.

Legs: Slender, unarmed, variegated, mainly green. Fore femora curved basally, shorter than fore tibiae. Mid femora and mid tibiae approximately equal length; hind femora shorter than hind tibiae. All femora thicker than corresponding tibiae.

MALE. (Figs 2, 5; 7-9, 13-14).

Head: Vertex with a pair of obscure dark tubercles on a transverse ridge between compound eyes. Occipital furrows distinct. Antennae 19-segmented, longer than middle of fore femora.

Thorax: Apterous, smooth. Pronotum rectangular, lateral sides parallel, longer than wide; posterior of longitudinal sulcus shallow. Mesonotum slender, posterior area of mesonotum with $\mathrm{H}$-shaped yellow stripe. Metanotum about 2.5 times the length of median segment, with a pair of short longitudinal yellow stripes near posterior margin.

Abdomen: Smooth, tergite II longer than wide. Parallel-sided from tergites II-VII. Tergites VIII-IX slightly expanded posteriorly, anal segment narrow. Tergite VIII slightly longer than tergite IX. Anal segment longer than tergite VIII, dilated into two distinct lobes, tapering posteriorly. Inner margins of lobes curved inwards, with more than 10 irregularly arranged teeth. Poculum bowl-shaped, posterior margin rounded, reaching anterior margin of anal segment. Cerci long, stout, cylindrical, pointing downward; the location of $2 / 3$ cerci slightly protuberating outwards, apical areas curved downwards and inwards, apices bluntly rounded.

Legs: Similar to female.

Eggs (Figs 4, 6). Capsule brown, acorns-shaped, posterior pole rounded, covered with a raised net-like structure, with granulations and short winkles. Micropylar plate oval, opening, covering less than half of capsule length, anterior margin slightly pointed; micropylar cup placed at the middle of posterior margin of micropylar plate. Median line short and shallow. Operculum dark brown, elliptical, concaved at the centre, swollen and wrinkled.

MEASUREMENTS. Length (in mm). Body (from anterior edge of head to posterior edge of anal segment): ㅇ 53.8-56.4, đ 49.6-52.6; head (without antennae): 우 3.6-3.9, ô 3.1-3.5;

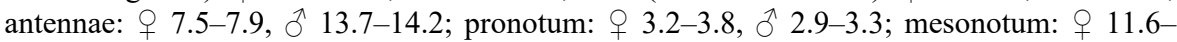

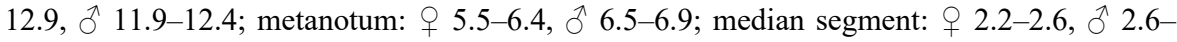
2.8; fore femora: 우 18.3-21.1, o 18.5-21.2; mid femora: 우 10.4-13.7, त $13.5-14.0$; hind femora: 우 12.7-17.2, 아 16.8-17.8; fore tibiae: ㅇ 20.7-24.3, 사 22.0-22.9; mid tibiae: 우 11.9-13.9, ð 13.4-14.2; hind tibiae: ㅇ 16.3-20.4, ठิ 18.8-19.8.

DIAGNOSIS. The new species is most similar to Interphasma lushanense, but differs from the latter in female, in I. lushanense, praeopercular organ of sternite VII narrower in apex but not elongate, posterior margin truncate; in new species praeopercular organ of sternite VII broad at its base, narrower and elongate in apex, and anal segment showing a small notch in the middle of posterior margin. Males differ from the lobes of the anal segment 
and cerci, in I. lushanense, lobes of anal segment wide at its base, middle of apical areas narrowed observably, cerci short; in new species, the lobes of the anal segment being broad at the base and gradually narrowing toward apex; and the cerci being long, robust and curved downwards.

DISTRIBUTION. China (Sichuan)

ETYMOLOGY. The new species is named after the type locality Huayingshan.

\section{Interphasma leigongshanense $\mathrm{Xu}$, Yang et Guo, 2010}

Type locality: China (Leigongshan, Guizhou).

NOTE. No material examined.

\section{Interphasma lizipingense Ho et Shi, 2013}

Type locality: China (Liziping, Shimian, Sichuan).

MATERIAL EXAMINED. China: Sichuan, Shimian, Liziping, 7.VIII 2019, 2守, $2 \widehat{\diamond}$, coll. Hai-Jian Wang (SICAU).

\section{Interphasma longnanense Chen et $\mathrm{He}, 2008$}

Type locality: China (Kangxian, Gansu).

NOTE. No material examined.

\section{Interphasma lushanense Chen et He, 2008}

Type locality: China (Lushan, Jiangxi).

TYPE MATERIAL EXAMINED. Holotype - + , China: Jiangxi, Lushan, 7.VIII 1935, coll. O. Piel (IZCAS). Paratypes: 10, same data as holotype; 1, 20, Jiangxi, Lushan, Dayueshan, 6.VIII 2018, coll. Bo-Liang Li (SICAU).

\section{Interphasma marginatum Chen et Zhang, 2008}

Type locality: China (Gaoligongshan, Yunnan).

TYPE MATERIAL EXAMINED. Holotype - $\hat{\sigma}$, China: Yunnan, Gaoligongshan, thermal spring, 6.VI 2007, coll. Xing-Rong Gao (BFU).

\section{Interphasma nigrolineatum Chen et $\mathrm{He}, 2008$}

Type locality: China (Menglun, Xishuangbanna, Yunnan).

TYPE MATERIAL EXAMINED. Holotype - $\hat{\jmath}$, China: Yunnan, Xishuangbanna, Menglun, 11.VI 1993, coll. Long-Long Yang (IZCAS).

OTHER MATERIAL EXAMINED. China: Yunnan, Xishuangbanna, Yaoxiang, 31.VII 2019, 2へ, coll. Sheng-Chuan Yang et Qi-Di Zhu (SICAU).

\section{I. shaanxiense Chen et He, 2008}

Type locality: China (Xigou, Yangxian, Shaanxi).

TYPE MATERIAL EXAMINED. Holotype - + , China: Shaanxi, Yangxian, Xigou, 14.VIII 1996, coll. Lu Sun (CAU). 
Type locality: China (Wolong, Sichuan).

MATERIAL EXAMINED. Holotype - + , China: Sichuan, Wolong, Yingxionggou, 21.VIII 1991, coll. Xing-An Li (BFU).

OTHER MATERIAL EXAMINED. China: Sichuan, Chongzhou, Anzihe, 10.IX 2016, 1 , , coll. Xiao-Qiang Guo (SICAU).

\section{Interphasma xinjiangense Chen et $\mathrm{He}, 2008$}

Type locality: China (Xinjiang).

TYPE MATERIAL EXAMINED. Holotype - $\widehat{\jmath}$, China: Xinjiang, 1957, coll. Comprehensive investigation team of the Ministry of forestry (unknown the exact data) (BFU).

\section{ACKNOWLEDGEMENTS}

We are grateful to professor San-An Wu and Dr. Zhi-Liang Wang (Beijing Forestry University); researcher Jun Chen and Dr. Kui-Yan Zhang (Institute of Zoology, Chinese Academy of Sciences) for their help during examining the type specimens. This work is funded by the National Natural Foundation of China (No. 31872268), and the Key project of the Education Department of Sichuan Province, China (No. 18ZA0386).

\section{REFERENCES}

Bradler, S. 2009. Die Phylogenie der Stab-und Gespenstschrecken (Insecta: Phasmatodea). Species, Phylogeny and Evolution, 2: 3-139. DOI: https://doi.org/10.17875/gup2009-710

Bragg, P.E. 1997. A glossary of terms used to describe phasmids. Phasmid Studies, 6: 24-33.

Brock, P.D., Büscher, T. \& Baker, E. 2020. Phasmida species file online. Version 5.0/5.0. Available from: http://phasmida.speciesfile.org/ (Accessed 13 June 2020)

Chen, S.C. \& He, Y.H. 2008. Phasmatodea of China. China Forestry Publishing House, Beijing. 476 pp. [In Chinese]

Chen, S.C. \& Zhang, P.Y. 2008. Five new species of stick insects from Yunnan province and description of male Cnipsomorpha colorantis (Chen et He) (Phasmatodea: Heteronemiidae, Phasmatidae). Entomotaxonomia, 30(4): 245-254.

Clark-Sellick, J.T. 1997. Descriptive terminology of the phasmid egg capsule, with an extended key to the Phasmid genera based on egg structure. Systematic Entomology, 22: 97-122. DOI: https://doi.org/10.1046/j.1365-3113.1997.d01-30.x

Hennemann, F.H. \& Conle, O.V. 2008. Revision of Oriental Phasmatodea: The tribe Pharnaciini Günther, 1953, including the description of the world's longest insect, and a survey of the family Phasmatidae Gray, 1835 with keys to the subfamilies and tribes (Phasmatodea: "Anareolatae": Phasmatidae). Zootaxa, 1906: 1-316. DOI: https://doi.org/ 10.11646/zootaxa. 1906.1.1

Ho, W.C. 2017. Contribution to the knowledge of Chinese Phasmatodea IV: taxonomy on Medaurini (Phasmatodea: Phasmatidae: Clitumninae) of China. Zootaxa, 4365(5): 501516. DOI: https://doi.org/10.11646/zootaxa.4365.5.1

Ho, W.C. 2020. New taxa of Clitumninae from Vietnam (Phasmatodea: Phasmatidae). Zoological Systematics, 45(2): 104-117. DOI: https://doi.org/10.11865/zs.202015 
Ho, W.C. \& Shi, F.M. 2013. A new species of the genus Interphasma Chen \& He, 2008 (Phasmida: Clitumninae: Medaurini) from Sichuan, China. Zootaxa, 3734(4): 492-496. DOI: https://doi.org/10.11646/zootaxa.3734.4.7

Xu, F.L., Yang, M.F. \& Guo, G.H. 2010. A new species of the genus Interphasma from China (Phasmatodea, Phasmatidea). Acta Zootaxonomica Sinica, 35(2): 395-397.

(C) Far Eastern entomologist (Far East. entomol.) Journal published since October 1994 Editor-in-Chief: S.Yu. Storozhenko

Editorial Board: A.S. Lelej, S.A. Belokobylskij, M.G. Ponomarenko, V.A. Mutin, E.A. Beljaev, E.A. Makarchenko, A.V. Gorochov, T.M. Tiunova, M.Yu. Proshchalykin, S.A. Shabalin, V.M. Loktionov

Address: Federal Scientific Center of the East Asia Terrestrial Biodiversity (former Institute of Biology and Soil Science), Far East Branch of the Russian Academy of Sciences, 690022, Vladivostok-22, Russia.

E-mail: storozhenko@biosoil.ru web-site: http://www.biosoil.ru/fee 